\title{
Climate change impact - residential unit
}

\author{
Ján Hollý1,*, and Adela Palková ${ }^{1}$ \\ ${ }^{1}$ STU Bratislava, Department of Building Construction, Radlinského 11, 81005 Bratislava, Slovakia
}

\begin{abstract}
The issue of climate change is undeniably demonstrating its presence. Consequently, there is a rising need to be prepared for upcoming threats by any means possible. One of the precautions includes obtaining the information characterizing the expected impact of global warming. This will allow authorities and other stakeholders to act accordingly in time. The article presents the assessment of the extent of impact of energyrelated construction solutions in dwelling type unit situated in Central Europe region under the 21 st century climate conditions. The findings represent eventual demands of energy for cooling and heating and its prospective savings. This is conducted by consecutively and automatically changing the parameters in individual simulation runs. As a basis for simulations, regionally scaled weather data of three different climate areas are used. These data are based on the emission scenarios by IPCC and are reaching to the year 2100. The selection of assessed parameters and climate data application are briefly explained in the article. The results of simulations are evaluated and recommended solutions are stated in regard to the specific energy-related construction changes. The aim is to successfully mitigate and adapt to the climate change phenomenon.
\end{abstract}

\section{Introduction}

As the building sector is one of the largest producers of greenhouse gases, it has a significant impact on the progress of global warming. Therefore, it should be in our interest to reduce the negative effects of the building industry and to prepare for the presumed consequences of incoming eventualities among which the rising temperatures pose one of the greatest threats.

The Intergovernmental Panel on Climate Change (IPCC) is the leading coordinator of the fight against climate change. IPCC brings together climate change experts who examine the development of the climate during the 21 st century. These presumptions are published as emission scenarios which contain information about future climate data. This article considers three basic scenarios: A1B (rapid economic growth, global population that peaks in mid-century and declines thereafter, and the rapid introduction of new and more efficient technologies, balance of all energy sources), A2 (very heterogeneous world, self-reliance and preservation of local identities, increasing global population, slower technological change), B1 (population as in A1, service and information economy, clean and resourceefficient technologies) [1].

\footnotetext{
${ }^{*}$ Corresponding author: jan.holly.pd@gmail.com
} 
We can expect temperature rise in all three scenarios. This puts in risk heat-sensitive people, rises cooling demands and induces aftereffects such as massive precipitation occurrence, fauna and flora migration and many more. On the other side, in the temperate zone with four year seasons, it lowers the heating demand and thus reduces the GHG emissions. But is it worth the negative aspects?

This article presents the findings of simulations with the utilisation of presumed future weather data as was conducted in several other studies [2-4] which investigated the effect of climate change in building industry. Findings in this article reveal the climate change impact on single-detached family house typical for the region. The results also show to what extent the specific construction adjustments affect energy demand of this specific building type.

\section{Simulation inputs}

\subsection{Weather data}

As a basis for adjustment of input values, daily temperature minima, maxima and average values were used. These were received as a courtesy from OMK KAFZM FMFI UK and represent conditions up to year 2100. The data are based on the KMMI regional climate model based on the German ECHAM5 model, derived from IPCC's Third assessment report (TAR). Other climate data crucial for energy simulation are used as original EnergyPlus weather data for the specific region as most of them do not change in the. Energy demand in three cities was examined: Hurbanovo (HU), one of the warmest cities in the region, Poprad (PP) one of the coldest places, affected by the High Tatras mountain climate and Bratislava (BA) with the climate conditions relatively in between the two aforementioned.

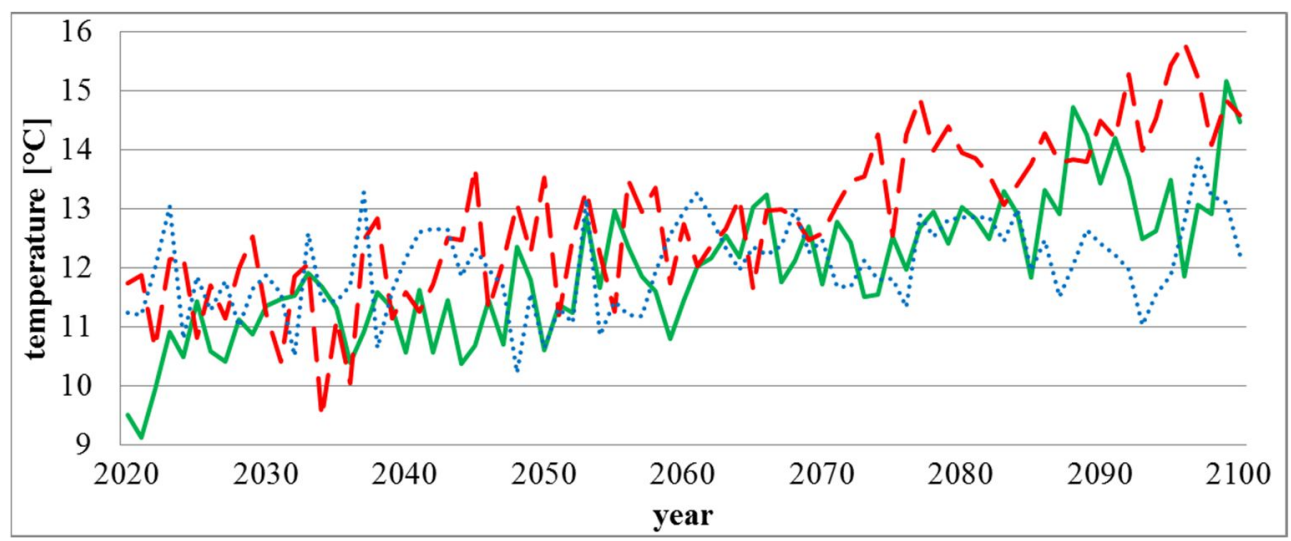

Fig. 1. Presumed course of yearly mean temperatures (A1B - cont; A2 - dashed; B1 - dotted) in BA.

EnergyPlus was used for conducting simulations. Its engine requires hourly weather data as a basis for calculating the energy consumption of a building. Therefore, the provided daily values of temperature had to be recalculated by a specific algorithm, utilising goniometric functions [5]. It was assumed that daytime minima are set one hour before sunrise and maxima two hours after the sun's highest position above the horizon (14:00), which is the reaction time of air required to warm up to a maximum temperature. Course of temperatures between these maxima and minima have the shape of sinusoids, adjusted by the daily temperature average. 


\subsection{Building model}

For the purpose of simulations, single-detached family house was chosen (Fig. 2), as it exemplifies widespread building type in the region. The layers of building's envelope are modelled to represent the thermal resistance derived from the Slovak standard which is expected to be mandatory in the year 2021 . In numbers, it is $R_{\text {ceiling }}=9.9\left(\mathrm{~m}^{2} . \mathrm{K}\right.$ )/W (for ceiling) and $\mathrm{R}_{\text {wall }}=6.5\left(\mathrm{~m}^{2} . \mathrm{K}\right) / \mathrm{W}$ (for walls). Widows glazing (was modelled separately from frames) consists of three panes, two of them coated, with gaps filled with argon, its thermal resistance is $\mathrm{U}_{\text {glass }}=0.69\left(\mathrm{~m}^{2} . \mathrm{K}\right) / \mathrm{W}$.

Infiltration is set to $\mathrm{n}_{50}=0.6 \mathrm{ac} / \mathrm{h}$ (Passive House requirements). Natural and mechanical ventilation are allowed, maintained automatically, based on room's occupancy, as the ventilation is set to provide fresh air by the amount of $71 / \mathrm{s}$ per person. Moreover, natural ventilation only occurs when the room temperature exceeds $23{ }^{\circ} \mathrm{C}$ and the difference between the indoor and outdoor air dry-bulb temperatures is more than $2{ }^{\circ} \mathrm{C}$.

Temperature setpoints are based on occupancy, meaning that when the room is occupied, heating or cooling thermostat is set to $20{ }^{\circ} \mathrm{C}$ or $25^{\circ} \mathrm{C}$ respectively $\left(17{ }^{\circ} \mathrm{C}\right.$ or $29^{\circ} \mathrm{C}$ when the room is unoccupied). Heating recovery is installed with the effectiveness of $80 \%$. Exterior shading is programmed to shade the windows when both of the following conditions are fulfilled: more than $120 \mathrm{~W} / \mathrm{m}^{2}$ of global solar energy radiates on window and outside air temperature is more than $21^{\circ} \mathrm{C}$. This is set to avoid summer overheating.
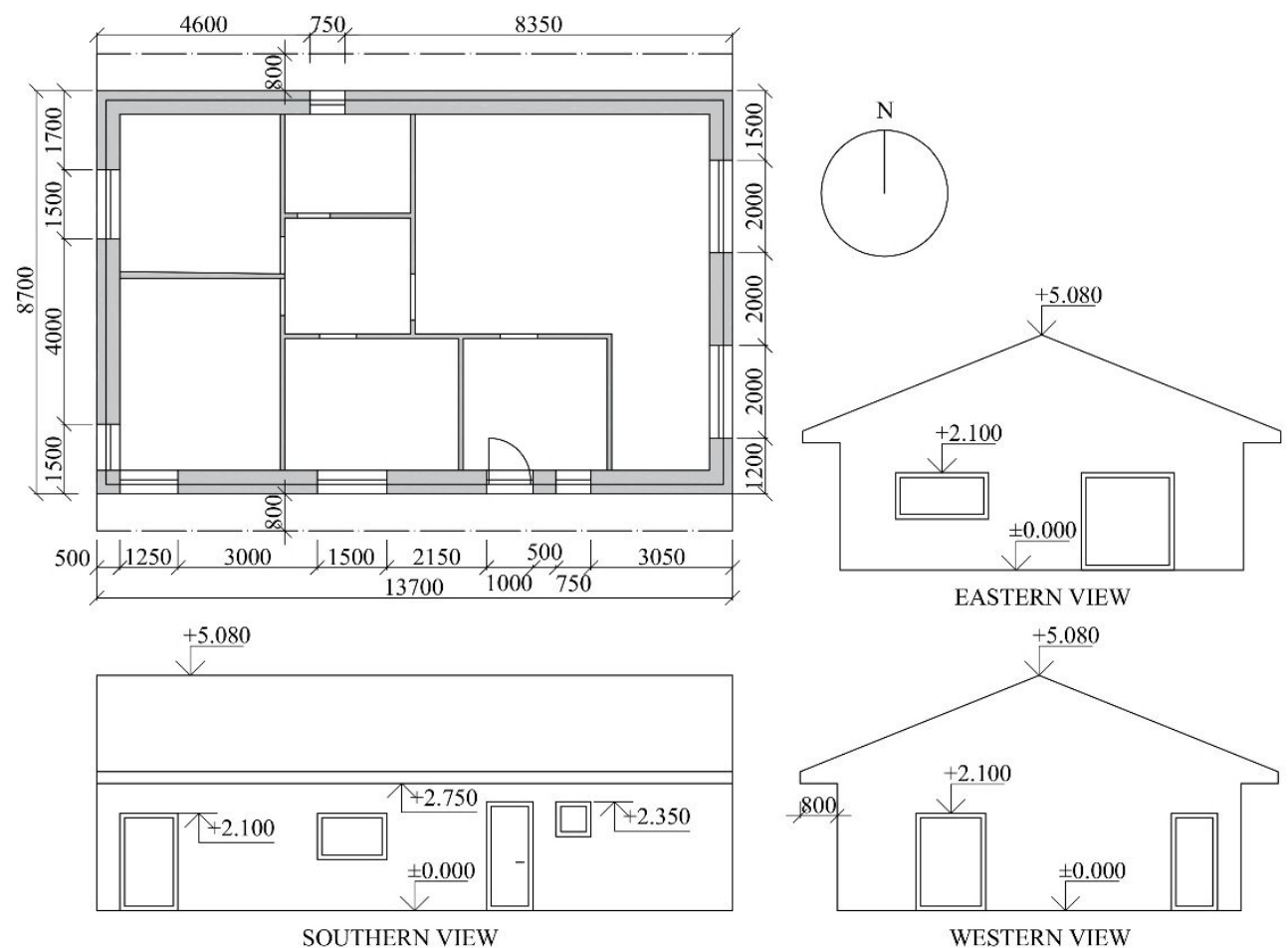

EASTERN VIEW

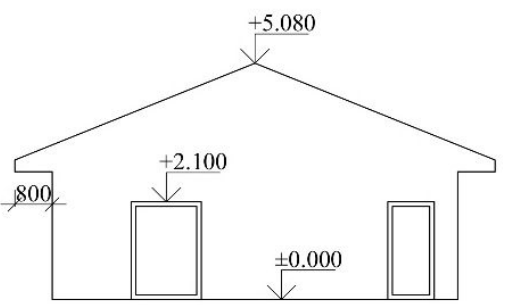

WESTERN VIEW

Fig. 2. Simulated model, single-detached family house.

\section{Construction alternatives}

To adapt to the temperature and to lower energy demands, specific construction changes have been made to evaluate their mitigating potential in the events of climate change. 


\subsection{Accumulation}

As the original building model was based on the common experience in the region, when the walls are made of aerated concrete blocks, and ceiling is made of thermal insulation cladded with plasterboards, building's accumulation capability is relatively low. In the "ACC" alternative, changes were made to increase the building's accumulation capability, while the thermal resistance was maintained as in the original (ORI) version. These changes were made to examine the potential of nocturnal ventilation.

Table 1. Construction characteristics of examined model versions.

\begin{tabular}{|l|r|l|r|r|r|r|}
\hline Constr. & $\begin{array}{c}\text { Model } \\
\text { version }\end{array}$ & \multicolumn{1}{|c|}{ Material } & $\begin{array}{c}\text { Thickness } \\
{[\mathrm{mm}]}\end{array}$ & $\begin{array}{c}\text { Conductivity } \\
{[\mathrm{W} / \mathrm{m} . \mathrm{K}]}\end{array}$ & $\begin{array}{c}\text { Specific heat } \\
{[\mathrm{J} / \mathrm{kg} . \mathrm{K}]}\end{array}$ & $\begin{array}{r}\text { Density } \\
{\left[\mathrm{kg} / \mathrm{m}^{3}\right]}\end{array}$ \\
\hline \multirow{4}{*}{ Walls } & \multirow{3}{*}{ ORI } & aerated concrete & 300 & 0.19 & 840 & 580 \\
\cline { 3 - 7 } & \multirow{3}{*}{ ACC } & mineral wool & 200 & 0.041 & 1000 & 115 \\
\cline { 3 - 7 } & & hollow ceramic & 380 & 0.18 & 960 & 790 \\
\cline { 3 - 7 } & \multirow{3}{*}{ ORI } & mineral wool & 160 & 0.037 & 1000 & 115 \\
\hline \multirow{3}{*}{ ORIing } & plasterboard & 15 & 0.22 & 1060 & 750 \\
\cline { 3 - 7 } & \multirow{2}{*}{ ACC } & mineral wool & 400 & 0.041 & 940 & 19 \\
\cline { 3 - 7 } & & reinforced steel & 150 & 1.43 & 2020 & 2400 \\
\cline { 3 - 7 } & & XPS & 330 & 0.034 & 2060 & 32 \\
\hline
\end{tabular}

\subsection{Window size}

To quantify the impact of window size on heating and cooling demand throughout the 21 st century, glazing area on the south facade of the building was doubled, while maintaining its original construction (triple $4 \mathrm{~mm}$ glazing, where two of the panes are coated, with $16 \mathrm{~mm}$ argon filled gaps; $\left.R_{\text {glass }}=0.69\left(\mathrm{~m}^{2} . \mathrm{K}\right) / \mathrm{W}\right)$. Window area on the south facade was increased from $4.7 \mathrm{~m}^{2}$ to $9.4 \mathrm{~m}^{2}$. Shading conditions are as in the original version (shading is on when more than $120 \mathrm{~W} / \mathrm{m}^{2}$ of global solar energy radiates on window and outside air temperature is more than $21^{\circ} \mathrm{C}$ ). Results are presented in the following section as "WIN" alternative.

\section{Results}

Following figures 3. -6 . represent 5-year moving average values for specified cases.
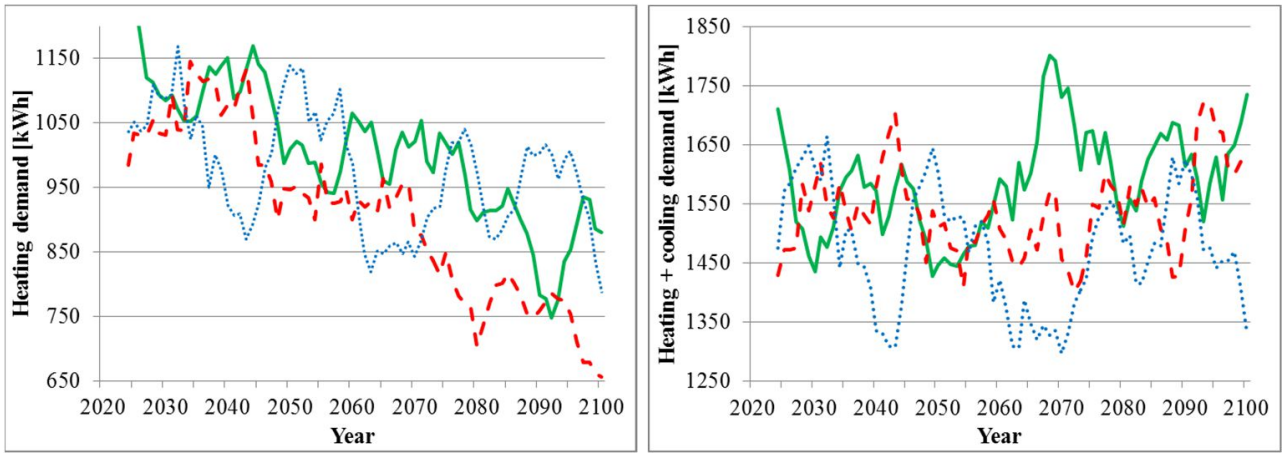

Fig. 3. Energy demands for Bratislava (BA) (A1B - continuous; A2 - dashed; B1 - dotted). 

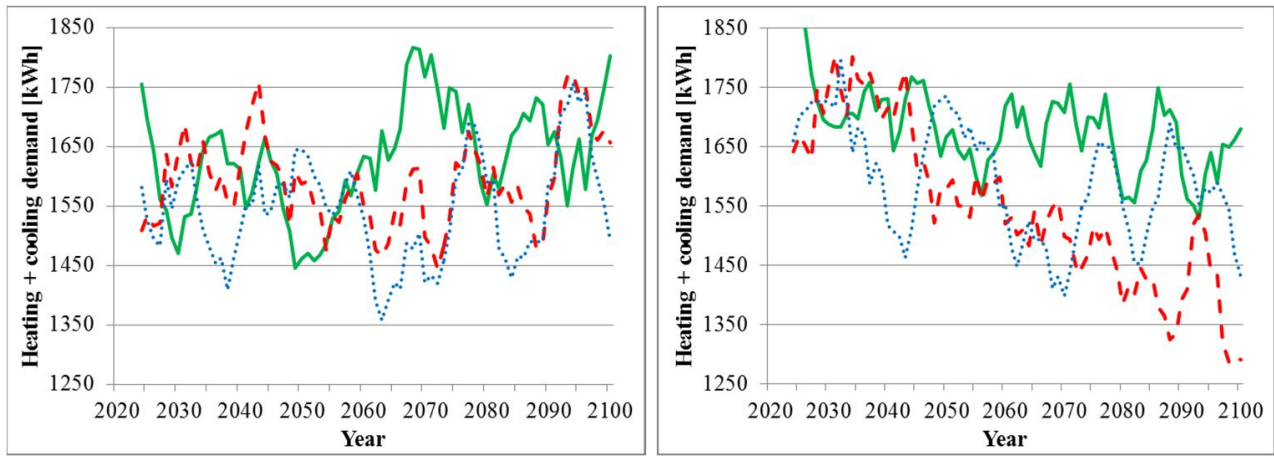

Fig. 4. Energy demands for HU (left) and PP (right) (A1B - continuous; A2 - dashed; B1 - dotted).
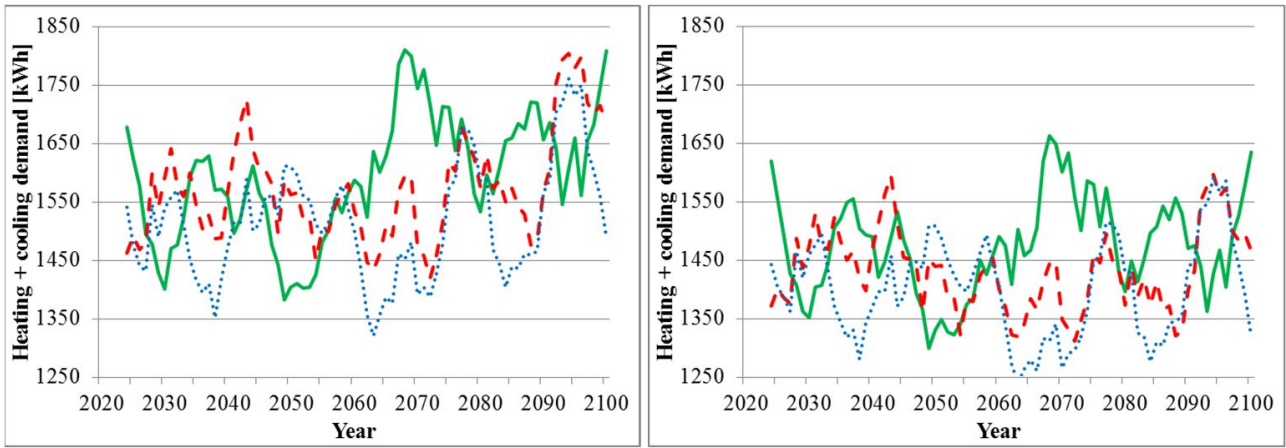

Fig. 5. Energy demands for HU in WIN alternative (left) and ACC alternative (right) (A1B continuous; A2 - dashed; B1 - dotted).
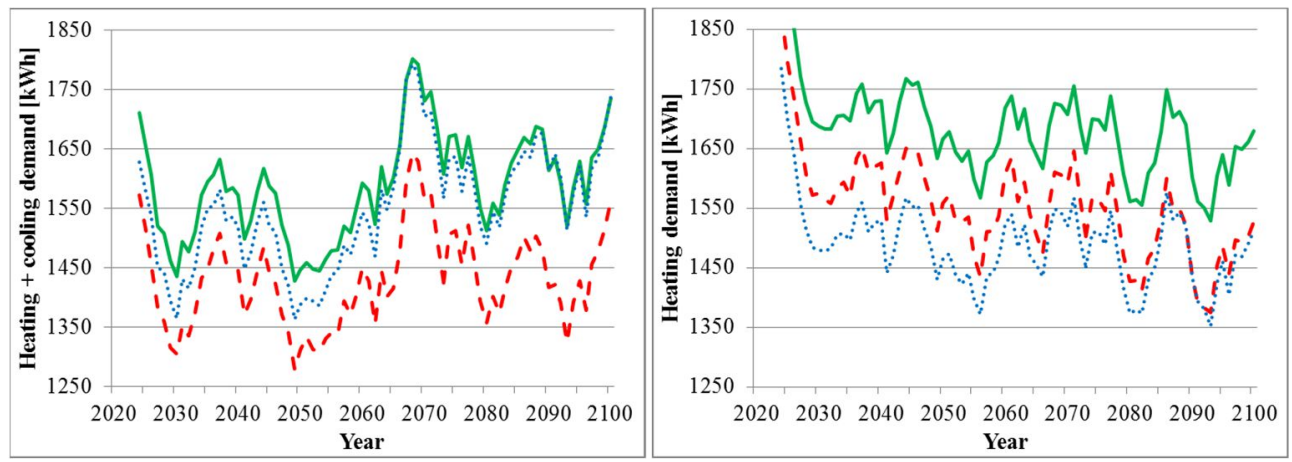

Fig. 6. Energy demands in BA (left) and PP (right), in A1B scenario (original model - continuous; ACC alternative - dashed; WIN alternative - dotted).

Several statements can be made according to the linear trend of the calculated demand values for the years $2020-2100$. Heating demand in Bratislava (BA) decreases in all three scenarios ranging from $13 \%$ in B1 scenario to $33 \%$ in A2 scenario (Fig. 3). Summation of heating and cooling demands shows decrease in B1 scenario (5\%) but increases in A2 scenario (5\%) due to the relatively high cooling demand at the end of the century (Fig. 3). Combined heating and cooling demand in Hurbanovo (HU) shows rising trend in scenarios A2 (4\%) and A1B (8\%), whereas B1 scenario seems to keep the steady tendency (Fig. 4). 
Because of the cold climate and thus relatively low cooling demands, combined energy demands in Poprad (PP) shows decreasing trend in all three scenarios: 10\% (B1), 11\% (A1B) and 25\% (A2) (Fig. 4).

Regarding the alternative building models, both the adjustments lowered energy demands, providing that the window shading is installed and reacts automatically to the radiation and temperature conditions. In Hurbanovo (HU), ACC alternative has higher potential due to the availability of nocturnal cooling (Fig. 5). Moreover, the effectivity of construction alterations changes throughout the century as is clearly seen in Fig. 6. Enlarging the windows on the south facade has more potential in early years of 21 st century (losing its utilizability in BA during the later years), while increasing the building's accumulation capability is crucial during the whole 21 st century.

\section{Conclusions}

This article described how the generated hourly values were subsequently used to estimate the energy consumption of the simulated building during the 21 st century. It is clear from the results that the global warming will have a significant impact on energy requirements in the residential building sector both in the temperate and cold zones of the central Europe region. In the means of adaptation and mitigation of climate change effects, several construction adaptations should be promoted, as it is shown to have sound effect on energy demand. Additionally, it is important to rationally utilize renewable energy sources, and use highly-efficient technologies. From the sustainability and environmental safety point of view of, the decisive element will be the conversion factor of the supplied energy.

Thanks to the OMK KAFZM FMFI UK for the provision of climatic data used as a basis for calculations. This research was supported by Scientific Grant Agency MŠVVŠ SR and SAV under VEGA 1/0685/16 and by the Mladý výskumník grant 1627 .

\section{References}

1. IPCC Special Report, Emissions Scenarios, Summary for Policymakers (2000)

2. M. Hamdy, S. Carlucci, P.-J. Hoes, J. L.M. Hensen, Building and Environment, 122, 307-323, (2017)

3. K. Weng, Energy Procedia, 105, 3727-3732, (2017)

4. T. van Hooff, B. Blocken, H.J.P. Timmermans a J.L.M. Hensen. Energy, 94, 811-820, (2016)

5. D.H.C. Chow, G. J. Levermore, Building Services Engineering Research and Technology, 28(3), 237-248, (2016) 